\title{
EL NACIMIENTO DE LOS ESTUDIOS \\ INTERNACIONALES SOBRE AMÉRICA LATINA: \\ COMENTARIOS A LAS OBRAS DE JOSÉ MARÍA \\ TORRES CAICEDO Y CARLOS CALVO A \\ MEDIADOS DEL SIGLO XIX
}

Carlos Marichal

Hace ya Cuatro decenios que se viene discutiendo entre historiadores cuándo y quiénes bautizaron a nuestra región América Latina. En su ensayo clásico, publicado en 1968 que fue pronto traducido al español, John Phelan abrió fuego con el argumento de que fue en el París de Napoleón III cuando comenzó a hablarse de la raza latino-americana y que fue entonces que la expresión cobró vigencia. ${ }^{1}$ Pero el profesor Phelan fue más allá y atribuyó la paternidad indirectamente a Michel Chevalier, antiguo saint-simoniano, economista, publicista y asesor del emperador en política exterior, lo cual contribuyó a espolear un debate historiográfico al vincular el concepto de América Latina con las políticas imperialistas francesas de la época. Es un hecho muy bien sabido que desde mediados de 1830, pero sobre todo a partir del decenio de 1850 , Chevalier había sido ideólogo de una política exterior panlatina de parte de Francia. Ello coincidía con la notable expansión económica francesa en el continente europeo desde mediados del siglo, pero también con el impulso al comercio exterior con las Américas (norte y sur), que entonces cobró un extraordinario dinamismo.

${ }^{1}$ John Phelan, "Pan-latinismo, French intervention in Mexico (1861-1867) and the genesis of Latin America", en Conciencia y autenticidad históricas (Escritos en homenaje a Edmundo O'Gorman), México, UNAM, 1968, pp. 279-298. 
Francia se colocó rápidamente de nuevo como el gran rival de Gran Bretaña, lo que contribuyó a afianzar en muchos debates políticos y científicos el contrapunto entre pueblos latinos, germanos y anglosajones. ${ }^{2}$

Sin embargo, el hecho es que Chevalier nunca utilizó la expresión "América Latina" como tal, sino que fue plasmada por otros autores en varios artículos publicados desde 1861 en la Revue des Races Latines y otros medios, mas no en la más prestigiosa y longeva Revue des Deux Mondes sino hasta 1865. Por otra parte, Phelan vinculaba, de alguna manera, el uso del nuevo concepto con la invasión francesa de México y el establecimiento del imperio de Maximiliano (1863-1867). Este planteamiento provocó la reacción de diversos estudiosos, en particular de Arturo Ardao, investigador uruguayo y pionero en historia intelectual latinoamericana decimonónica. Ardao encontró su campeón en el olvidado escritor colombiano José María Torres Caicedo, quien seguramente puede considerarse el verdadero padre de la expresión por varias razones, la más importante siendo su labor proselitista a favor de la unidad de los países latinoamericanos y su uso constante del término en revistas, libros y debates en París entre fines del decenio de 1850 y principios de 1880. El bautizo se habría producido con la publicación del poema "Las dos Américas" en 1857, publicado en el periódico que Torres Caicedo entonces dirigía, del cual extraemos algunas estrofas:

\section{LAS DOS AMÉRICAS}

\section{$[\ldots]$}

La raza de la América latina,

$\mathrm{Al}$ frente tiene la sajona raza,

Enemiga mortal que ya amenaza

Su libertad destruir y su pendón.

${ }^{2}$ El libro clásico sobre la impresionante expansión francesa desde 1850 (sobre todo en la Europa Latina) es Rondo Cameron, Francia y el desarrollo económico de Europa, 1800-1914, Madrid, Tecnós, 1971. El aumento del comercio francés con América del Norte y Sudamérica en la época lo precisa Carlos Calvo en múltiples cuadros estadísticos en las introducciones a las obras que comentamos en este ensayo. 
La América del Sur está llamada

A defender la libertad genuina,

La nueva idea, la moral divina,

La santa ley de amor y caridad.

El mundo yace entre tinieblas hondas:

En Europa domina el despotismo,

De América en el Norte, el egoísmo,

Sed de oro e hipócrita piedad.

Tiempo es que esa Virgen que se alza

Entre dos Océanos arrullada

Y por los altos Andes sombreada,

Deje su voz profética escuchar.

El cielo que la dio bellezas tantas,

La señaló un magnífico destino:

Nueva Vestal, conservará el divino

Fuego que nunca deberá cesar.

Ella será la que levante firme

Templo a la Libertad y a los Derechos,

$\mathrm{Al}$ rodar carcomidos y deshechos

Los palacios que albergan el error;

Que sus selvas y llanos dilatados

A la Razón ofrecerán altares,

Y por sus playas cambiarán sus lares

Cuantos anhelen libertad, amor.

\section{El Correo de Ultramar}

(París, 15 de febrero de 1857)

Posteriormente, otro investigador, Miguel Rojas-Mix, publicó un libro en el cual concordaba con Ardao en que fueron latinoamericanos residentes en París los que forjaron la expresión, haciendo especial hincapié en el papel del chileno Francisco Bilbao (desterrado de su patria por su radicalismo), quien había asociado "América" y "Latina" en algunos ensayos, así como en un discurso pronunciado en París en junio de 1856 ante un 
público de unos treinta latinoamericanos que se habían reunido para protestar contra la agresión de Walker (en Nicaragua) y para prevenir el peligro de futuras invasiones norteamericanas en el continente. $^{3}$

Más tarde, el prolífico investigador francés, Paul Estrade, entró al ruedo y concluyó a partir de una serie de prolijas investigaciones sobre revistas parisinas de la época que, en efecto, no fue sino hasta los años entre 1861 y 1865 que el nombre de "América Latina" comenzaría a usarse con frecuencia. En la Revue du Monde Coloniale en esos años se utilizó la expresión "Amérique du Sud" 57 veces, mientras que "Amérique Latine" fue recogida unas 45 veces, de las cuales 22 menciones se debían a la pluma de Torres Caicedo. En la Revue des Deux Mondes, la expresión se utilizó apenas tres veces en 1865 , mas no antes. ${ }^{4}$

En resumidas cuentas, como el propio Estrade señalaba, es evidente que fue en París que el término (concepto) se acuñó y que estuvo fuertemente influenciado por la difusión e intensidad del debate más general sobre la latinidad y el destino de la Europa Latina. A estas discusiones no eran ajenos los exiliados y, sobre todo, los diplomáticos latinoamericanos en París, quienes fueron los principales protagonistas de una creciente proyección de escritos acerca de América Latina, algunos siendo autores de los primeros libros que llevaron este nombre en sus títulos. De hecho, el primer autor que así bautizó una obra (en varios volúmenes) fue el futuro internacionalista Carlos Calvo en su obra titulada Colección completa de los tratados, convenciones, capitulaciones, armisticios y otros actos diplomáticos de todos los Estados de la América Latina (11 vols., París, 1862-1867) y luego en su compilación Anales históricos

${ }^{3}$ Véase Miguel Rojas-Mix, "Bilbao y el hallazgo de América Latina: unión continental, socialista y libertaria”, Caravelle (Toulouse), núm. 46, 1986; y su libro Los cien nombres de América, Barcelona, Lumen, 1991.

${ }^{4}$ Paul Estrade explica en su texto "Del invento de 'América Latina' en París por latinoamericanos, 1856-1889”, en París y el mundo ibérico e iberoamericano, París, Université de Paris X, Nanterre, 1998, pp. 183-184, que cuatro de sus alumnos llevaron a cabo memorias de DEA detalladas sobre las revistas parisinas de la época, con los resultados mencionados. 
de la revolución de la América Latina, acompañados de los documentos en su apoyo (París, 1864-1867, 5 vols.).

Al mismo tiempo, debe señalarse el uso del término en dos obras contemporáneas de Torres Caicedo: su folleto Bases para la formación de una Liga Latino-Americana, impreso en la capital francesa en febrero 1861, que luego amplió y transformó en su libro Unión Latino-Americana, publicado en París en 1865, al igual que su no menos importante Ensayos biográficos y de crítica literaria sobre los principales publicistas, historiadores, poetas y literatos de la América latina, París, Baudry, 1868.

Por consiguiente, la difusión del término "América Latina" (o "Latinoamérica") partió de una coyuntura contradictoria. Se vinculaba con la difusión del debate sobre la latinidad y lo panlatino, que fue expresado de manera violenta en el escenario internacional por una serie de intervenciones militares efectuadas en los decenios de 1850 y 1860 en la región hispanoamericana, todos con fuerte impronta colonialista. Los exiliados y diplomáticos latinoamericanos en París veían con gran recelo o rechazo el expansionismo colonialista, primero de los Estados Unidos en Centroamérica en la década de 1850 y luego del gabinete español de la Unión Liberal, que promovió intervenciones militares en la región, como fue la ocupación militar de Santo Domingo en 1861, seguida por la guerra naval con Perú en 1865. Aún más preocupantes fueron las políticas imperiales de Napoleón III, que tuvieron su expresión más violenta en la invasión y ocupación de gran parte del territorio de México en 1862 por el ejército francés, a pesar de la resistencia del gobierno de Benito Juárez y de sus protestas internacionales. En pocas palabras, dentro del pequeño pero significativo grupo de diplomáticos latinoamericanos en París a mediados de siglo, entre los cuales había un número no despreciable de escritores, se gestó una discusión profunda acerca de la historia y del futuro destino de las naciones de la América española y portuguesa. Es más, puede sugerirse que de sus discusiones y publicaciones habrían de nacer los primeros estudios internacionales de América Latina con una impronta moderna. 
LOS DIPLOMÁTICOS Y ESCRITORES LATINOAMERICANOS en París y el papel pionero de Torres Caicedo

Como ha argumentado concienzudamente Arturo Ardao, fue el colombiano José María Torres Caicedo, radicado en París desde 1853, quien llevó a cabo la más amplia y constante obra como periodista y publicista de la causa de la unión latinoamericana en la capital francesa. ${ }^{5}$ Era un diplomático polivalente -algo bastante común en la época-, siendo ministro plenipotenciario de Colombia en París, Londres y la Santa Sede, pero luego también de Venezuela, con representación en París y Bruselas, y unos años más tarde de El Salvador, en estas dos últimas ciudades. Debido al escaso desarrollo de la carrera diplomática en la mayoría de los países latinoamericanos, no era nada extraño que se eligieran como representantes a escritores de nota o políticos bien conectados para ocupar los cargos de ministros plenipotenciarios; de manera similar, se solía elegir a comerciantes para los puestos de cónsules.

Una de las características de las labores de los diplomáticos latinoamericanos en Europa a mediados del siglo xix era que no requerían una dedicación tiempo completo, lo que les dejaba tiempo para escribir. Torres Caicedo, que ganaba muy poco como representante de Venezuela, pudo destinar tiempo a redactar artículos y ensayos en la prensa europea: desde 1857 y durante muchos años contribuyó a El Correo de Ultramar (1842-1886), periódico literario y político que se publicaba dos veces al mes en París. Había sido fundado por un rico comerciante francés con intereses en ultramar, y logró crear una amplia red de suscripciones tanto en las Antillas como en la América española. El atractivo de este periódico consistía en que combinaba notas políticas con numerosas noticias sobre la moda en París así como artículos literarios. Contó, sobre todo, con plumas de intelectuales, políticos y artistas españoles como Eugenio de Hartzenbusch, Mariano Urrabieta,

${ }^{5}$ José María Torres Caicedo (1830-1889) muy joven escribió en varios periódicos radicales en Bogotá en 1849 y 1850, pero pronto tuvo que emigrar para recuperarse de una herida sufrida en un duelo, al parecer por razones políticas. Se pasó los años de 1851 y 1852 en Nueva York hasta recalar en París, donde viviría la mayor parte del resto de su vida: Ardao, América Latina y la Latinidad, p. 59. 
Eugenio de Ochoa, Emilio Castelar, Manuel Fernández y González, pero también con algunos hispanoamericanos. ${ }^{6}$ Torres Caicedo, quien pasó a ser su director en 1857, cuidó mucho la relación con España y estableció estrechos vínculos con Eduardo Asquerino, editor del periódico madrileño La América (1857-1886). Desde su fundación, éste fue importante vehículo político y literario, señalado por Ardao como la publicación periódica de su tipo de mayor difusión en el mundo de lengua española, con suscripciones en España, gran parte de la América española (incluidas veinte agencias de suscripción en México) y ciertas ciudades de los Estados Unidos. Torres Caicedo publicó un artículo en La América en 1858 en el cual usa la expresión "América Latina", primicia en los medios madrileños. ${ }^{7}$

Merced a su labor como publicista y editor entusiasta de la defensa de la cultura y de la soberanía de las repúblicas hispanoamericanas, en junio del año de 1861 los diplomáticos hispanoamericanos acreditados en París y Londres le dirigieron a Torres Caicedo una nota destinada a reconocer sus aportaciones. Decía el documento:

Es a usted, Señor, a quien se debe haber levantado el glorioso pendón de los Estados Hispano-Americanos; usted en periódicos españoles y franceses ha defendido los derechos soberanos de esas Repúblicas, siempre que algunas Naciones poderosas han pretendido desconocer la justicia que a ellas asistía. Siga usted en su obra filantrópica, en la cual trabaja desde hace ocho años con tanto celo como desinterés y obtendrá los beneficios de todos cuantos rinden culto a lo bello, lo bueno y lo grande $[\ldots]^{8}$

Firmaron como afectísimos "compatriotas", un conjunto distinguido que incluía a Pedro Gálvez, ministro plenipotenciario de Perú, Carlos Calvo, encargado de negocios del Paraguay, Juan

${ }^{6}$ Catherine, Sablonierre, "El Correo de Ultramar (1842-1886)".

7 Ardao, América Latina y la latinidad, pp. 211-217. Véase también Leoncio López-Ocón, Biografía de "La América": una crónica hispano-americana del liberalismo democrático español (1857-1886), Madrid, csic, 1987.

${ }^{8}$ Ardao, América Latina y la latinidad, pp. 81-82. 
Bautista Alberdi, ministro plenipotenciario de la Confederación Argentina, Andrés Santa Cruz, antiguo protector de la Confederación Perú-Boliviana y antiguo ministro plenipotenciario, Víctor Herrán, ministro plenipotenciario de Honduras y de El Salvador y los ministros de la Confederación Granadina, Guatemala, Ecuador y Venezuela.

Se trataba de un verdadero $c l u b$ de diplomáticos. Es interesante notar con todo que entre ellos se contaban tanto escritores y publicistas destacados como veteranos políticos. Juan Bautista Alberdi, probablemente el autor latinoamericano más prolífico de la época, escribía constantemente en periódicos de París y de América, a lo cual se agregaba su profusa producción de folletos y tratados políticos, legales y económicos. Gran parte de los textos suyos, redactados en su larga estancia en París (1854-1880), se han convertido en clásicos de la ciencia política latinoamericana. A su vez, desde 1860, Carlos Calvo, encargado de negocios del Paraguay, comenzaba a destacar como joven escritor, internacionalista, hecho confirmado por su traducción de la obra fundamental de Enrique Wheaton, Historia de los progresos del derecho de gentes, publicada en París a mediados de 1861. Por su parte, hay que mencionar al decano del grupo de diplomáticos latinoamericanos, el mariscal Santa Cruz. Él había encabezado la Confederación Peruana-Boliviana (1838-1844), pero fue desterrado a Europa en 1845 tras el derrumbe de este experimento político binacional: se le acordó una pensión de 6000 pesos para vivir en Francia y desde el decenio de 1850 fue nombrado ministro plenipotenciario de Bolivia y negoció diversos tratados antes de su muerte en 1865 .

Uno de los más activos propulsores de la unidad latinoamericana era el diplomático peruano, Pedro Gálvez Egúsquiza, y con él, tanto Torres Caicedo como Carlos Calvo estrecharon lazos. El gobierno de Perú, encabezado por el general Ramón Castilla, estaba empeñado en estos años en defender los principios de autodeterminación y de no intervención. Castilla había nombrado en 1855 a Pedro Gálvez como ministro plenipotenciario para los países de la América Central, Nueva Granada y Venezuela, y allí cumplió un importante papel en el respaldo a la defensa de Costa Rica a raíz de las amenazas que provocó la invasión de Nicaragua por 
los filibusteros de William Walker. También obtuvo la adhesión a su política americanista de los gobiernos de El Salvador y Guatemala, naciones puestas en riesgo por la ambigua posición de las autoridades estadounidenses. Castilla y Gálvez ejercieron un papel clave en la redacción y firma del Tratado Continental firmado en Santiago de Chile el 15 de septiembre de 1856 entre Perú, Ecuador y Chile para asegurar la soberanía y la unidad política y comercial de los Estados americanos.

En 1859 Gálvez fue nombrado ministro plenipotenciario del Perú en Francia, y luego en 1860 asumió también la tarea de representar a Perú ante el gobierno español, aunque siguió residiendo en París. Es interesante notar que en los archivos histórico-diplomáticos del Perú se encuentra una nota de esta época de José María Torres Caicedo al ministro de Relaciones Exteriores de Perú, con una solicitud suya para que el gobierno peruano auspiciara la publicación de un periódico para la defensa de los derechos e intereses de las repúblicas Hispano Americanas (1860). ${ }^{9}$ La razón era sencilla: el gobierno peruano era entonces el más rico de toda América Latina gracias a los ingentes ingresos provenientes de las exportaciones del guano, recurso que era propiedad del Estado, si bien comercializado por empresas privadas.

Como puede observarse en otra correspondencia diplomática que está registrada en los archivos diplomáticos peruanos, hacia mediados del siglo xix, el gobierno de Ramón Castilla acostumbraba financiar artículos en periódicos en Europa con objeto de promover una imagen positiva para el país y sus productos de exportación. ${ }^{10}$ Es éste un tema que merece ser explorado en mayor detalle a nivel comparativo, ya que la mayoría de los gobiernos latinoamericanos siguieron el ejemplo peruano en épocas posteriores, destinando, en ocasiones, sumas importantes para financiar

${ }^{9}$ En catálogo en línea del Archivo histórico central del Ministerio de Relaciones Exteriores de Perú, documento 28 de la Correspondencia diplomático del año de 1860, http://www.rree.gob.pe/portal/ArchivoCentral/Catalogo/ACInven tario.nsf/

${ }^{10} \mathrm{El}$ portal del Ministerio de Relaciones Exteriores del gobierno peruano es una fuente de gran interés para los historiadores. Ver en http://www.rree.gob.pe/ portal/archivos 
artículos que pudieran redundar en más inversiones, comercio o inmigración. El gobierno peruano fue pionero también en dedicar cuantiosos fondos para adquirir y difundir las primeras compilaciones sobre relaciones internacionales de América Latina que fueron editadas en París por Carlos Calvo.

\section{La breve carrera diplomática de Carlos Calvo en el Río de la Plata y París, 1854-1863}

Se ha señalado que entre los diplomáticos latinoamericanos que habrían de ejercer un papel decisivo en los tempranos estudios y compendios de relaciones internacionales de América Latina desde principios de la década de 1860 se encontraba Carlos Calvo, quien ejerció un papel especial por motivo de sus compilaciones de tratados así como de documentos históricos de las guerras de independencia de los países latinoamericanos. A ello habría que agregar que con el correr del tiempo, Calvo se convertiría en uno de los internacionalistas más destacados y leídos de Europa, sobre todo por sus grandes manuales, muy difundidos e influyentes entre los especialistas en derecho internacional, y utilizados por la mayor parte de las escuelas de derecho en Francia, Bélgica y Alemania y por numerosos diplomáticos de todo el mundo hasta fines del siglo xIx.

Para conocer mejor la trayectoria y las estrategias políticas y profesionales de Calvo, es necesario considerar primero algunos elementos de su biografía, para pasar luego a un resumido análisis de las características más destacadas de sus compilaciones dedicadas a la historia de las relaciones internacionales de América Latina. Carlos Calvo (1822-1906), miembro de una familia de comerciantes rioplatenses, había nacido y recibido su primera educación en Montevideo, y ya adolescente se trasladó a estudiar derecho en Buenos Aires. En 1844 viajó por primera vez a Europa, donde permaneció algunos años. Así bien es de suponer que posteriormente se dedicó a actividades vinculadas con los negocios mercantiles de su familia, que tenía oficinas en Buenos Aires, Montevideo, Paraná así como corresponsales en Europa. Carlos y sus hermanos formaron una red mercantil y financiera muy cercana al general 
Urquiza y, sin duda, ayudaron al financiamiento de sus campañas. Después de la batalla de Caseros en 1852, cuando se produjo la derrota de Rosas por Urquiza, y a partir del establecimiento del gobierno de la Confederación Argentina, toda la familia recibió encargos consulares: Carlos fue nombrado vicecónsul en Montevideo, su hermano Nicolás Antonio recibió el mismo cargo en Le Havre; Adolfo en Río de Janeiro y Diego en Asunción. A su vez, su cuñado, Juan José Soto y Villegas, fue nombrado secretario de la legación en Río de Janeiro. Este hombre sería a partir de 1856 copropietario del importante periódico, La Reforma Pacífica, fundado por Nicolás Calvo en Buenos Aires para intentar acercar al gobierno del Estado de Buenos Aires con el gobierno de la Confederación. ${ }^{11}$

Sin embargo, después de la separación del Estado de Buenos Aires de la Confederación en 1854, en una muestra de extrema versatilidad política, Carlos Calvo se pasó al otro bando y se convirtió en agente consular del gobierno de Buenos Aires en Montevideo. Siguieron existiendo algunas dudas durante un tiempo acerca de sus relaciones con la Confederación, pero finalmente se desligó de sus viejos aliados, no sin antes provocar considerable confusión. En su correspondencia consular, se observa que proporcionó valiosa información a las autoridades en Buenos Aires sobre expediciones secretas que incluían la contratación de centenares de hombres armados que fueron organizados por los agentes militares y financieros de la Confederación desde el Uruguay con objeto de cruzar el Río de la Plata, invadir la campiña y eventualmente llegar a sitiar a la ciudad de Buenos Aires. ${ }^{12}$

Resulta curioso observar que, medio siglo después de estos episodios, el alto funcionario mexicano, José Yves Limantour habría de resaltar la capacidad y astucia política y diplomática de Carlos Calvo en los momentos que siguieron a la derrota de Buenos Aires en 1859 a manos del ejército de Urquiza. Señalaba en un texto muy poco conocido:

${ }^{11}$ La información familiar y política tomada del estudio biográfico de Eduardo Ricardo Pérez Calvo, Vida y trabajos de Carlos Calvo... (1996), pp. 21-25.

${ }^{12}$ La correspondencia ha sido rescatada recientemente por Eduardo Pérez Calvo, en la obra Vida y trabajos de Carlos Calvo, capítulos 4 y 5. 
Desde los años de 1858 y 1859, cuando las diversas Provincias del Río de la Plata se desgarraban unas a otras, en medio de una tormentosa guerra civil, nuestro prohombre [Carlos Calvo] tuvo parte en las negociaciones que, a la postre, dieron por resultado la cesación de la lucha fratricida. El general Francisco Solano López, hijo del Presidente del Paraguay, Don Carlos Antonio López, fue el mediador en dichas negociaciones, y a él corresponde seguramente el principal mérito de esa obra de paz; pero también es menester señalar que el exquisito tacto, saber profundo y las cualidades personales de Carlos Calvo, consejero y hombre de confianza del general mediador, influyeron considerablemente en que se obtuviera tan satisfactoria solución. ${ }^{13}$

Francisco Solano López había sido nombrado comandante en jefe del ejército paraguayo en 1846 por su padre, Carlos Antonio López, presidente y virtual dictador del Paraguay desde 1840 hasta 1862. El primero ya había asumido muchas de las facultades de gobierno desde fines del decenio de 1850, incluyendo una buena parte de la política exterior. El acuerdo al que hacía referencia Limantour era el "Pacto de San José de Flores", firmado el 10 de noviembre de 1859 entre Urquiza, presidente de la Confederación Argentina y las fuerzas de Buenos Aires al mando del general Mitre y sus allegados para establecer un acuerdo de convivencia del Estado de Buenos Aires dentro de la Confederación.

Recientemente se ha recuperado y publicado una serie de extractos de correspondencia entre Francisco Solano López y Carlos Calvo en 1860 (poco después de la firma del pacto mencionado), cuando se le ofreció al segundo la Legación de Paraguay en Londres y París, esencialmente para negociar los diferendos con el gobierno británico. ${ }^{14}$ A su regreso a Asunción, Solano López escribió a Calvo el 17 de enero de 1860 y ofreció nombrarlo Encargado de Negocios del Paraguay en Londres y París por un periodo de

${ }^{13}$ José Yves Limantour, "Memoria sobre la vida y obra de D. Carlos Calvo", discurso de incorporación como miembro del Instituto de Francia, París, 1910, 39 pp. Limantour ocupó el sillón de Calvo en el Instituto: Calvo había fallecido en 1906.

${ }^{14}$ En un archivo virtual de la historia del Paraguay se reproduce algo de la correspondencia de Francisco Solano López: véase http:/ /www.bvp.org.py/ 
dos años prorrogables, con un sueldo de 6000 pesos anuales. ${ }^{15}$ Calvo aceptó inmediatamente y salió para Londres con objeto de llevar a cabo las negociaciones para intentar reestablecer relaciones entre Paraguay y Gran Bretaña, pero cuidando de resolver previamente una serie de conflictos pendientes. Al principio no tuvo éxito ya que el secretario de Asuntos Exteriores de Inglaterra, Lord John Russell, se negó a recibirlo, acusando a Paraguay de haber agredido a ciudadanos ingleses y de provocar conflictos entre un barco inglés y uno de la armada paraguaya. Más adelante, Calvo tuvo la habilidad de lograr "la intervención oficiosa del señor Thouvenal, ministro de Negocios Extranjeros de Francia, y del Conde de Flahaut, embajador de Francia en Londres", y muy amigo de Russell. ${ }^{16}$ Con ello se fueron reestableciendo las relaciones diplomáticas entre Paraguay y Gran Bretaña. ${ }^{17}$

Evidentemente, Carlos Calvo no era un hombre fácil de manipular, especialmente cuando tenía claramente definidas sus metas profesionales y personales. Aparte de las negociaciones mencionadas, Calvo ya tenía el firme propósito de convertirse en un internacionalista de reputación en tiempo récord en Europa, aunque para ello necesitaba recursos. El gobierno del Paraguay incluyó "viático hasta el lugar de residencia"; pero una vez que Calvo estaba en Londres y había alquilado una residencia, existe el testimonio de que solicitó un aumento de fondos para poder cubrir sus gastos en el nivel "que corresponde a un representante diplomático en Europa”. Solano López se molestó por el tono de las demandas, pero al parecer accedió a otorgarle más viáticos. De hecho, debió facilitar fondos bastante amplios, pues al trasladarse a París a mediados de 1860 Calvo se lanzó pronto a varios proyectos editoriales ambiciosos

15 Ibid., carta del 17 de enero de 1860 de Solano López a Calvo.

${ }^{16}$ Limantour, "Memoria sobre la vida...", p.10. Paradójicamente, debe notarse que precisamente en esta época Flahuat y Russell estaban en estrecha relación secreta, planeando la intervención militar en México.

${ }^{17}$ Para un recuento pormenorizado de las negociaciones emprendidas debe consultarse el texto autobiográfico de Carlos Calvo publicado en 1864 en París por la Librarie A. Durand, titulado Una página de derecho internacional o la América del Sur ante la ciencia del derecho de gentes moderno. 
en la Ciudad Luz, los cuales requerían el pago de escribas, traductores e impresores.

Su primera publicación en París, sin embargo, era una obra ya editada en Montevideo, la cual hizo reimprimir: se trataba de la traducción de la obra fundamental de Enrique Wheaton, Historia de los progresos del derecho de gentes, que aparece publicada en París en 1861, con ventas en la librería A. Durand y en la librería española de Madame C. Denné-Schmitz. Al mismo tiempo se lanzó a un proyecto mucho más ambicioso que era su obra mayor Colección completa de los tratados, convenciones, capitulaciones, armisticios y otros actos diplomáticos de todos los Estados de la América Latina, publicada secuencialmente desde el año siguiente y hasta 1867, hasta completarse un total de 11 volúmenes. ${ }^{18}$

Dedicó dicha compilación al Emperador Napoleón III, porque, al decir de Calvo, era el estadista europeo que más se interesaba por América Latina. En este sentido, resultan sobradamente justificadas algunas de las críticas de Juan Bautista Alberdi con respecto a su compatriota, a quien consideraba un trepador y un oportunista: "En cuanto a prebendas pecuniarias, la Legación de Paraguay le ha dado más que todos los baratillos de que se ocupó en su vida. En ese punto representa a su gobierno a las mil maravillas, porque hace de la política y de comercio, una misma cosa, como los generales López". ${ }^{19}$

Sin embargo, también es justicia hacer notar que Alberdi estaba muy celoso por el hecho de que Calvo pronto recibió reconocimientos importantes del gobierno francés, incluida la Legión de Honor en 1864 por su compilación de tratados. También es menester decir que Calvo redactó el prólogo de su obra antes de la intervención tripartita en México, lo que le salvó de tener que explicar con claridad su posición con respecto a la invasión francesa de una república latinoamericana. De hecho, en sus famosos textos de derecho público posteriores, habría de mostrarse siempre destacado

${ }^{18}$ El mismo año aparece la traducción al español del primer volumen de la obra de Carlos Calvo con el título Recueil Complet des Traités des Etats de l'Amérique Latine, París, A. Durand, 1862.

${ }^{19}$ Decía Alberdi en sus Cartas Inéditas, p. 192. 
campeón de la soberanía nacional y especialmente del derecho de los Estados latinoamericanos de juzgar ciudadanos extranjeros de acuerdo con la legislación nacional del país donde se encontraba el extranjero: de allí habría de nacer la famosísima "Cláusula Calvo", que sigue siendo evocada en numerosos conflictos contemporáneos de carácter internacional entre agentes públicos y empresas privadas o extranjeros con negocios en el país en cuestión.

\section{PREHistoria de la DiPlomática latinOAMERICANA: Carlos Calvo y la Colección de Tratados}

En la larga introducción de su compilación de tratados, Calvo señala la abundancia de fuentes utilizadas y destaca, especialmente, aquellas de la época colonial. En su obra recopiló los tratados entre todas las potencias europeas con respecto a los distintos territorios de la América española y portuguesa desde el siglo Xvi hasta principios del siglo xIx. No obstante, debe señalarse en réplica a la crítica de Alberdi, quien sugirió que este autor escondía sus fuentes, que la verdad es que Calvo señala con precisión su deuda a las grandes compilaciones de tratados reunidos por sus contemporáneos, Abreu, Cantilo y Borge de Castro entre otros, a los cuales fue agregando gran cantidad de documentos de otras compilaciones y materiales del Archivo General de Indias en Sevilla. Es más, al final del primer volumen incluye un largo repertorio de fuentes sobre libros y documentos fundamentales y mapas por espacio de más de 200 páginas. Esta bibliografía y listado de documentos constituyen una muy interesante guía de fuentes con la que se contaba a mediados del siglo xix en París sobre la América española y portuguesa.

Calvo y sus escribientes utilizaron sobre todo compilaciones de documentos, monografías y fuentes primarias que localizaron en el British Museum, en la Biblioteca Imperial de París y en el Archivo General de Indias en Sevilla. Es evidente que tuvo que contar con una serie de auxiliares que ayudaron a copiar la mayor parte de los documentos, que fueron pagados inicialmente por la legación paraguaya, pero después de 1864 con otros recursos. No obstante, se observa un plan bastante coherente de trabajo, diseñado 
por Carlos Calvo, quien era un hábil director de las labores de la compilación. Por otra parte, en contraste con anteriores tratadistas españoles y portugueses, combinaba los textos y tratados de ambas naciones, España y Portugal, lo cual resultaba una novedad y contribuía a incorporar a Brasil y Portugal dentro de la literatura en lengua española sobre las relaciones internacionales. ${ }^{20}$ Este fue, por consiguiente, un temprano logro muy "latinoamericano" de Calvo.

En la introducción a su obra de los tratados latinoamericanos, Calvo resume primero la exposición del plan de trabajo editorial que se ha planteado, y luego ofrece al lector unas cuarenta páginas bien documentadas sobre el aumento considerable del comercio entre los países de Latinoamérica y Europa, especialmente entre 1850 y 1860, con énfasis en el incremento del intercambio con Francia. Incluye un gran número de tablas comparativas de población y comercio de los países latinoamericanos, que había reunido de los almanaques y de series estadísticas que requerían considerable trabajo de investigación.

El primer volumen de la Colección de Tratados comienza con una reproducción parcial del Tratado de Tordesillas (1493) y documentos de los primeros años de la conquista de las Américas por españoles y portugueses seguido por una compilación de materiales que se referían al siglo xvi. Concluye este volumen inicial con un glosario de más de treinta páginas de definiciones de términos de relaciones internacionales, que presagian una labor posterior que emprendería en un Diccionario de relaciones internacionales sobre esta temática, y que se publicó veinticinco años más tarde en Berlín.

Los siguientes volúmenes de la compilación de tratados realizada por Calvo y su equipo incluyeron una gran cantidad de documentos diplomáticos de los siglos XVI, XVII Y XVIII, y llegan hasta un par de años antes del estallido de la independencia de los países latinoamericanos. El verdadero interés que tiene este repertorio

${ }^{20}$ Fue de especial utilidad para Calvo la recientemente publicada compilación de J. F. Borges de Castro (Colecçao de tratados, convençoes, contratos... de Portugal de 1840 a 1859, Lisboa, 1859, 9 volúmenes), la cual, sin duda, sirvió como modelo principal para su propia obra. 
para un lector moderno es que hace reflexionar sobre la larga historia de las relaciones internacionales (inter-imperiales) antes del establecimiento de las naciones independientes y el establecimiento de sus propias relaciones diplomáticas.

De hecho, pensamos que puede calificarse esta experiencia colonial muy compleja como la larga prehistoria de las relaciones internacionales de América Latina. Y, en nuestra opinión, ofrece materiales muy interesantes para estudios en el futuro para valorar sus aportaciones. ${ }^{21}$

\section{Los Anales de Carlos Calvo de las independencias LATINOAMERICANAS}

Recopilar los documentos internacionalistas de la época colonial era solamente el primer objetivo de la labor de Carlos Calvo, quien se había fijado una serie de metas más ambiciosas. Ello se observa en la introducción de su nueva y complementaria compilación titulada, Anales históricos de la revolución de la América Latina, acompañados de los documentos en su apoyo. Desde el año 1808 hasta el reconocimiento de la independencia de ese extenso continente, publicado en cinco volúmenes entre 1864 y 1867 por su editor y librero principal en París, A. Durand. Allí señalaba algunas de sus metas: "Para el segundo período, mi primer pensamiento fue reunir todos los documentos que se refieren a la hermosa época de la independencia de los pueblos hispano-americanos". ${ }^{22}$ Sin embargo, afirmaba que llegó a la conclusión de que juntarlos con los materiales de época anteriores,

${ }^{21}$ Para más comentarios en este sentido, véase la "Introducción" a la edición electrónica por Fundación MAPFre, por J. Alberto Navas Sierras, compilador de este disco compacto tan útil para la investigación histórica de las relaciones internacionales de América Latina en el siglo xix. Véase en la colección Clásicos Tavera, el CD titulado Textos clásicos y documentación sobre la Independencia de América, J. Alberto Navas Sierra, (comp.), Fundación MAPFRE/Tavera, Serie II, vol. 3, Madrid, 2002.

22 Carlos Calvo, Anales históricos de la revolución de la América Latina, acompañados de los documentos en su apoyo. Desde el año 1808 hasta el reconocimiento de la independencia de ese extenso continente, París, A. Durand, vol. 1, 1864, p. XuIx. 
podría provocar una considerable confusión para el lector al mezclar documentos de la Colonia con aquellos posteriores a la Independencia: por ello decidió emprender una nueva compilación.

Su obra Anales históricos de la revolución de la América no es de ninguna manera exhaustiva. De hecho tiende a ser una compilación de documentos históricos centrados más bien en la independencia de los países del Río de la Plata, Chile, Perú, con muy escasos documentos referentes a la Gran Colombia. ${ }^{23}$ A su vez, conviene subrayar que apenas contiene documentación acerca de Brasil, Centroamérica o México, aunque falta una revisión más prolija en los extensos volúmenes de dicha obra para confirmar esta afirmación. Calvo prometió preparar y publicar una tercera sección con los tratados y convenios modernos de los Estados de América Latina, y afirmó que había realizado una buena compilación con la colaboración de sus colegas, ministros o encargados de negocios, en París. De hecho, citaba a los mismos autores que, como hemos relatado anteriormente, firmaron la nota en honor a Torres Caicedo en 1861, pero agregaba los nombres de A. R. Ardouin de Haití, Marcoleta de Nicaragua, Lafond de Costa Rica, los señores Rosales de Chile y el cónsul general de Chile en París, Francisco Fernández Rodella, todos los cuales le habrían proporcionado copias de documentos diplomáticos. Agrega que no podía incluir documentos de México o de Ecuador por la absoluta falta de materiales en sus respectivas legaciones en París. ${ }^{24}$

A pesar de sus buenas intenciones, Calvo no llegó a producir una compilación de tratados que fuera más allá de los años de las guerras de independencia (1810-1825), conque quedó trunca su promesa de cubrir de los años de 1825-1860, salvo unas escasísimas excepciones. En este sentido, su labor puede verse como incompleta (Alberdi lo acusaba precisamente de eso), pero se encuentran referencias tanto a estos documentos compilados como a

${ }^{23}$ Muy probablemente no quiso tocar el tema de Venezuela y Colombia por el hecho que ya existía la gran compilación de 22 tomos de Documentos para la vida pública del Libertador Bolívar, publicadas en Caracas en 1840.

${ }^{24}$ Las referencias son de la página L de la "Introducción" a la Colección de Tratados (1862), vol. 1, en la que explica su proyecto tanto de los Tratados como de los Anales. 
otros adicionales en sus obras posteriores, entre ellas su monumental Derecho internacional, teórico y práctico de Europa y América, publicado en París por los editores D'Amyot, Durand et Pedone Lauriel, y más especialmente en las ediciones ampliadas en francés de 1880-1881 de cuatro volúmenes, y de 1887-1888 en cinco volúmenes. Allí pueden encontrarse intercaladas una gran cantidad de referencias a las relaciones internacionales latinoamericanas del siglo xix, al igual que en su Dictionnaire de droit internacional public et privé, publicado en 1885 en Berlín. En esta última obra se incluye una extensa bibliografía de los principales autores que habían escrito obras importantes sobre las relaciones internacionales de los países latinoamericanos hasta esa fecha.

\section{LA DIFUSIÓN DE LA OBRA: LIBRERÍAS Y EDITORES FRANCESES EN ESPAÑa Y LA COLOCACiÓN EN LA AMÉRIGA ESPAÑOla}

Una última cuestión que nos interesa comentar sobre estas tempranas obras sobre relaciones internacionales latinoamericanas se refiere al financiamiento de la producción y difusión de su Colección... de los tratados... de la América Latina, así como de sus Anales históricos de la revolución de la América Latina... de 1808 hasta el reconocimiento de la independencia, los cuales, en conjunto, sumaban 16 volúmenes. Es evidente que dicha tarea no pudo llevarse a cabo sin disponer de considerable tiempo y recursos financieros para las tareas editoriales (incluidos el copiado y corrección), así como la impresión y la difusión de las obras.

En carta personal a Juan María Gutiérrez, Juan Bautista Alberdi comentó la obra de su rival en los términos más acerbos:

Dándose a editor de trabajos que no ha escrito, [Carlos Calvo] hace publicar bajo su nombre archivos inservibles que ya estaban publicados, y los vende como Derecho Público Americano y en el interés de América Latina en la forma y con los resultados siguientes: al Perú por valor de doscientos mil francos, que el gobierno de ese país ha puesto a disposición en Francia; y al Paraguay por una suma equivalente [...] El ministro de Perú en París [Gálvez], uña y carne con Paraguay, fue 
ahora poco a Lima; se hizo ministro de hacienda, firmó el pago de esa subvención, y enseguida volvió a París, donde hoy está $[\ldots]^{25}$

[Alberdi agregaba:]

Como en Francia [Calvo] no tuvo que hacer nada, porque el Paraguay no tenía cuestión aquí, ocupó su tiempo en el negocio de libros. Reprodujo las compilaciones de Cantillo y de Abreu. El negocio estaba en que se había asegurado comprador de sus obras, como las llamó, al gobierno de Paraguay y otros gobiernos $[\ldots] .{ }^{26}$

Lo cierto es que Calvo pudo difundir centenares de ejemplares de su obra debido a los apoyos señalados y la capacidad de convencer a gran número de periódicos, personas y oficinas en América Latina del interés de contar con estas compilaciones. Además, es claro que les interesaba tanto al gobierno peruano como al paraguayo utilizar la obra de Calvo como medio para proyectar su política exterior. No obstante, después de 1864, Calvo ya no contó con estos recursos debido a su renuncia al cargo diplomático que había ocupado. Puede sugerirse que las críticas tan ácidas del solitario (Alberdi) reflejaban el hecho de que le costaba trabajo aceptar que hubiese otro escritor argentino en París que alcanzara fama intelectual y que, además, fuera recibido en las sociedades científicas, mientras que él enfrentaba dificultades en obtener un similar reconocimiento por parte de la élite política y académica del imperio de Napoleón III. También le tenía resentimiento a Calvo porque su eterno rival, Domingo Faustino Sarmiento, "lo adora, lo admira y ha hecho de él, oficialmente, una especie de Grocio argentino". ${ }^{27}$

No hay duda de que sería de utilidad hacer una evaluación equilibrada y detallada de la obra de Calvo como internacionalista en la Europa de la segunda mitad del siglo xix. Que era astuto para los negocios editoriales, como lo demostró ser en los oficios

${ }^{25}$ Cita recogida de la correspondencia de Eduardo Pérez Calvo, en la documentada y bien investigada obra Vida y trabajos de Carlos Calvo (1996), p. 169.

26 Ibid. p. 173.

27 Ibid. p. 174. 
políticos y diplomáticos, es bastante evidente. Pero también debe resaltarse que después de dejar su puesto de Encargado de Negocios de Paraguay en 1863 se dedicó esencialmente a escribir y dar clases de derecho internacional y ganó un gran reconocimiento por ello en muchos círculos académicos y diplomáticos europeos.

Sus compilaciones fueron reseñadas y elogiadas (en general) en un buen número de revistas y periódicos europeos y latinoamericanos: en 1862 en el Journal des Savants de Paris, Revue des Deux Mondes, Moniteur Universel, Revue du Monde colonial, Mémorial Diplomatique; en 1863 en Journal des Economistes y Home and Foreign Review, así como en los periódicos latinoamericanos Mercurio de Lima, Ferrocarril de Santiago y Los Andes (Guayaquil). En este último periódico, de amplia circulación en Ecuador y Nueva Granada (y además con puntos de venta desde Chile hasta Centroamérica), el periodista Ramón López hizo una larga reseña el 23 de enero de 1864 de los Anales históricos de la revolución de la América Latina, compilados por Calvo. Señalaba que era una obra original: "Calvo observa con sentimiento que la América latina, descubierta, conquistada y poblada por la Europa no es, sin embargo, tan conocida como debe serlo". Más puntualmente sobre el título de la obra, López indicaba: "Compréndase bajo la calificación de América Latina, los Estados independientes y soberanos que se han constituido en medio del nuevo continente de los antiguos dominios de las coronas de España, Portugal i Francia [...] Ocupan una superficie de 390466 millas cuadradas, con 32312 542 habitantes". ${ }^{28}$ Estos comentarios nos parecen significativos porque reflejan el hecho de que en la prensa sudamericana comenzaba a difundirse el uso del término "América Latina", como resultado de obras publicadas en París y leídas en América.

Conviene resaltar, en este sentido, la importancia de París en esta época como punto de encuentro entre latinoamericanos y europeos, y la proyección de Francia en relación con un comercio cada vez más intenso de mercancías, modas, ideas y modelos culturales que los países latinoamericanos importaban de los países europeos.

${ }^{28}$ Pudimos consultar el ejemplar de Los Andes en la magnífica hemeroteca de la Biblioteca Central de la Universidad de la Plata, donde se lleva a cabo una importante labor de microfilm de periódicos del siglo XIX. 
De hecho, París fue probablemente el punto más importante de exportación de libros y revistas a los países latinoamericanos, como lo demuestran el considerable número de libreros/editores que se dedicaban a este negocio, incluida la exportación de textos en francés y también gran número de traducciones al español. En los años de 1860 algunas de las librerías, que además figuraban como editoras y que publicaban numerosos textos para el público español y latinoamericano (en francés y español), incluían aquellos que hicieron trabajos para Calvo como A. Durand, Garnier Hermanos y Hachette y Cia: las mismas tenían estrechas relaciones con la librería Bailly-Baillière en Madrid. Algunas de estas empresas evolucionarían en la dirección de constituirse como editoriales y con cierta especialización temática. Por ejemplo, en la década de 1880 figura A. Durand \& Pedone-Lauriel como Editeur; y es claro que publicaba mucho en el terreno de derecho y derecho internacional, como lo atestiguan los pies de imprenta de las obras de Calvo publicadas en ese decenio en París.

El legado de Carlos Calvo, internacionalista LATINOAMERICANO EN EUROPA, 1864-1906

Pese a las críticas de Alberdi, Carlos Calvo se convirtió muy rápidamente en uno de los internacionalistas más destacados de Europa y de América Latina desde fines del decenio de 1868, lo cual puede atribuirse al éxito que tuvieron sus obras de compilación de tratados y documentos latinoamericanos, pero aún más a su tratados de derecho internacional público y privado (la primera edición fue de 1868), que habría de difundir ampliamente merced a sucesivas ediciones, ampliadas.

Sin duda, Calvo no era el único internacionalista latinoamericano de la época. Podemos señalar a un puñado de escritores que escribieron de manera bastante regular sobre temas internacionales de Latinoamérica en los primeros tres cuartos del siglo xix, entre ellos el propio Alberdi y su compatriota Amancio Alcorta, el uruguayo Andrés Lamas, los chilenos Bello, Amunategui y Barros Arana, los peruanos Gregorio Pérez Gomar y Francisco García Calderón, 
el colombiano José Torres Caicedo, el panameño Justo Arosemena, el mexicano Ignacio Vallarta, entre otros. Pero no cabe duda de que el individuo que logró una mayor sistematización del derecho internacional (y del lugar de Latinoamérica en este terreno) fue Carlos Calvo. Pese a que alcanzó a ser muy conocido en Europa como internacionalista, más frecuente hoy son referencias a la influencia de su prédica y sus obras en determinados ámbitos políticos y de derecho en América Latina, especialmente por la gran influencia de su crítica a las intervenciones extranjeras (en particular la intervención francesa en México entre 1862 y 1867), la cual quedó explicitada en su tratado de derecho internacional de 1868. De allí que la "cláusula y la doctrina Calvo" se convertirían en puntos de referencia inevitable en los litigios que tuvieron lugar en una larga secuencia de conflictos internacionales en Latinoamerica, especialmente a raíz de las intervenciones militares extranjeras en el primer tercio del siglo xx, pero también hoy en día en litigios internacionales entre gobiernos latinoamericanos y compañías multinacionales. Los textos de derecho internacional que se refieren a esta temática son numerosos. ${ }^{29}$ En cambio, las referencias a la obra internacionalista muy extensa de Carlos Calvo son relativamente escasas, lo cual parece reflejar el carácter aún incipiente de los estudios históricos sobre los orígenes de los estudios internacionalistas de especialistas de la región a lo largo del siglo xix. Este tema, sin embargo, requeriría una investigación prolija, especialmente en la prensa, al estilo del reciente y magnífico estudio de Pérez Vejo sobre la visión de España en el debate público mexicano a mediados del siglo xix, basada en la revisión de docenas de periódicos y revistas mexicanos y españoles. ${ }^{30}$

En resumidas cuentas, en contra de lo que afirmó John Phelan, la difusión del término "América Latina" no fue simplemente resultado de la política imperial francesa, la cual se hundió estrepitosamente tras la derrota del régimen de Maximiliano en México a

29 Véanse los textos de Arrellano García, García Mora, Sepúlveda, Shea y Tamburini citados en la bibliografía final de este ensayo para una muestra de la riqueza de referencias en la literatura jurídica.

30 Tomás Pérez Vejo, España en el debate público mexicano, 1836-1867: Aportaciones para una historia de la nación, El Colegio de México/ENAH/INAH, 2008. 
raíz de la resistencia de las fuerzas patrióticas y militares encabezadas por Benito Juárez. En este sentido, fue significativa la difusión del término y concepto de América Latina en esta época a partir de los esfuerzos políticos de los diplomáticos y los escritores expatriados en la capital francesa que se esforzaron por promover una imagen de unidad latinoamericana frente a agresores extranjeros, aunque, de hecho, sus críticas al neocolonialismo rara vez pasaban a convertirse en una crítica directa al régimen autoritario de Napoleón III, probablemente por temor a represalias personales o de carácter diplomático contra sus propios países. A la larga, fue fundamental la difusión lenta pero sostenida de escritos de latinoamericanos y franceses en la segunda mitad del siglo XIX -destacan las contribuciones de José María Torres Caicedo y Carlos Calvo-, pues contribuyeron a crear una mayor conciencia de los paralelos y puntos de encuentro culturales, históricos, literarios y políticos entre los propios países latinoamericanos.

\section{Anexo}

La cláusula y la Doctrina Calvo en constituciones latinoamericanas y un ejemplo de su importancia en controversia contemporánea en derecho internacional.

La doctrina Calvo tuvo una importancia notable en la historia latinoamericana y del derecho interamericano, con influencia en una primera hora a raíz de la derrota del imperio de Maximiliano y del ejército de ocupación francesas por las fuerzas patriotas encabezadas por Benito Juárez, presidente de México. ${ }^{31}$ Posteriormente la Doctrina Calvo fue fundamental en la génesis de la Doctrina Drago, formulada a principios del siglo xx por el jurista argentino Luis María Drago y en la Doctrina Estrada, formulada por el canciller mexicano Genaro Estrada en 1930.

${ }^{31}$ Sobre este tema y sobre las campañas internacionales de Juárez en defensa de la soberanía de México, véanse los ensayos en Patricia Galeana (ed.), Presencia internacional de Juárez, México, Centro de Estudios de México Carso, 2008. 
También ha ejercido importancia en la jurisprudencia constitucional de la región. En 1950, de acuerdo con el jurista Manuel García Mora, la cláusula Calvo se incluía en las constituciones de Bolivia (artículo18), Ecuador (artículo 177), la de Honduras (artículo 25), la de México (artículo 27), la de Perú (artículo 32) y la de Venezuela (artículo 108). Por su parte, la doctrina Calvo se expresaba en las constituciones de Costa Rica (artículo 12), Cuba (artículo 19) y la de El Salvador (artículo 45). ${ }^{32}$

Posteriormente se han realizado numerosas reformas constitucionales en los distintos países latinoamericanos, pero, a título de ejemplo, puede señalarse que los principios de la Doctrina Calvo se encuentran plasmados en el artículo 63 de la Constitución Política del Perú de 1993, la Constitución boliviana de 1967 en el artículo 24, la de Guatemala (1985) artículo 29 y la de Ecuador (1998) artículo 14, al igual que en los principios contenidos en el artículo 89 de la Constitución Política de México.

También tiene expresión en documentos de derechos internacional, como por ejemplo lo resuelto en la Novena Conferencia Panamericana (Bogotá, 1948), que ratificó la Doctrina Calvo en el ámbito regional con la Carta de la Organización de los Estados Americanos en su artículo 15.

Sin embargo, en tiempos recientes en los tribuales de arbitraje internacional la validez de la cláusula Calvo es contestada por los Tratados de Inversión Bilaterales (BIT) que han venido firmando empresas multinacionales y los gobiernos latinoamericanos desde 1990 en adelante, hasta el punto que hoy hay más de dos mil de estos tratados especificos y generalmente permiten saltarse las normas del tipo tradicionales cubiertas por la Doctrina Calvo.

Un ejemplo reciente de la larga duración y vigencia del pensamiento de Carlos Calvo lo ofrece el testimonio del gobierno de Venezuela en su controversia con empresas petroleras internacionales en 2008. Abajo incluimos un extracto de una parte de un documento relevante por sus observaciones históricas y porque demuestra su

${ }^{32}$ Manuel García Mora, "The Calvo Clause in Latin American Constitutions and International Law”, Marquette Law Review, vol. 33, núm. 4, 1950, p. 208. 
vigencia contemporánea en litigios internacionales, especialmente entre empresas multinacionales y gobiernos soberanos: ${ }^{33}$

“Asalto contra la soberanía..."

La empresa Exxon-Mobil introduce una petición de arbitraje ante el Centro Internacional de Arreglo de Disputas Relativas a Inversiones (CIADI) y logra además que una corte de Nueva York ordene un embargo en contra de bienes de Petróleos de Venezuela Sociedad Anónima (PDvsa) [...] En lo jurídico se trata, ni más ni menos, de un intento de arrebatarle a Venezuela su soberanía de jurisdicción, es decir, el derecho a decidir sus controversias utilizando sus propias leyes y tribunales. Soberanía es la ilimitada potestad de un Estado de sancionar sus propias leyes, aplicarlas e interpretar mediante sus órganos jurisdiccionales las controversias que surjan sobre dicha aplicación. Basta eliminar una de estas potestades para aniquilar la soberanía.

\section{"La doctrina Calvo defiende la soberanía de jurisdicción..."}

Para comprender el significado de este debate en América Latina es preciso hacer un poco de historia. La invasión de Francia e Inglaterra a México en 1861 alertó la conciencia de los juristas latinoamericanos. Ya para 1868 el diplomático internacionalista argentino Carlos Calvo desarrolló en su obra Derecho internacional teórico práctico la doctrina de que un Estado independiente, en virtud del principio de igualdad de los Estados, no podía estar sometido a la ingerencia de otros Estados. Afirmó asimismo que los extranjeros no podían gozar de mayores derechos y privilegios que los nacionales, y debían solucionar sus controversias ante los tribunales internos del Estado territorial. Convencidos por esta doctrina, varios países

${ }^{33}$ Ministerio de Poder popular para la Comunicación Gobierno Bolivariano, 10 de febrero de 2008, http://www.minci.gob.ve/opinion/7/174267/exxon-mo bil_contra_venezuela.html 
latinoamericanos, entre ellos Bolivia, Honduras y Venezuela, incluyeron en sus constituciones y legislaciones una norma que fue conocida como "Cláusula Calvo", relativa a los contratos celebrados con inversionistas extranjeros, que impedía a éstos resolver las controversias sobre tales pactos acudiendo al llamado "recurso de protección diplomática” en el exterior, y les imponía dirimir sus reclamaciones única y exclusivamente en los tribunales del Estado receptor y de acuerdo con las leyes de éste.

\section{"Nuestras constituciones acogen la doctrina Calvo"}

Siguiendo esta doctrina, la Constitución de la República de Venezuela sancionada el 29 de marzo de 1901 dispone en su artículo 139 lo siguiente:

Ningún contrato de interés público celebrado por el Gobierno Federal o por el de los Estados, por las Municipalidades o por cualquier otro Poder Público, podrá ser traspasado, en todo o en parte, a gobierno extranjero; y en todos ellos se considerará incorporada, aunque no lo esté, la cláusula siguiente: "Las dudas y controversias de cualquier naturaleza que puedan suscitarse sobre este contrato y que no puedan ser resueltas amigablemente por las partes contratantes, serán decididas por los Tribunales competentes de Venezuela de conformidad con sus leyes, sin que por ningún motivo o por ninguna causa puedan ser origen de reclamaciones extranjeras". Las sociedades que en ejercicio de dichos contratos se formen deberán establecer domicilio legal en el país, para todos sus efectos, sin que esto obste para que lo puedan tener a la vez en el extranjero.

A los constituyentistas de esa época no faltaba patriotismo ni previsión. Año y medio después, el 2 de diciembre de 1902, las flotas del imperio inglés, alemán e italiano bloquearon y bombardearon Venezuela para cobrar por la fuerza nuestra Deuda Externa. Desde entonces, para evitar atropellos de esa índole generados por contratos con extranjeros o deudas derivadas de ellos, figura en todas las constituciones venezolanas una norma semejante, como 
por ejemplo el artículo 49 de la Constitución de 1936. Así hemos defendido tradicionalmente el atributo de soberanía de jurisdicción, vale decir, el derecho de Venezuela de decidir según sus propias leyes y por sus propios tribunales las controversias sobre los contratos de interés público.

\section{Bibliografía}

Alberdi, Juan Bautista, Cartas inéditas a Juan María Gutiérrez y a Félix Frías, recopilación e introducción de Jorge M. Mayer y Ernesto A. Martínez, Buenos Aires, 1953.

— El crimen de la guerra, texto presentado al concurso realizado por la Ligue Internationale et Permanente de la Paix, con sede en París, 1869 [reedición en São Paulo, 1994 por A-Z Editora].

— El Brasil ante la democracia de América: las disensiones de las repúblicas del Plata y las maquinaciones del Brasil, 1868 [reedición en Buenos Aires, 1946, por ediciones El Libro Ejemplar].

Ardao, Arturo, Génesis de la idea y el nombre de América Latina, Caracas, Centro de Estudios Latinoamericanos Rómulo Gallegos, 1980.

América Latina y la latinidad, México, unam, 1993.

Arellano García, Carlos, "Evolución de la cláusula Calvo y la zona prohibida en el Derecho constitucional mexicano y en el Derecho internacional", en La Revolución Mexicana a 100 años de su inicio. Pensamiento social y jurídico, México, IIJ-Unam, 2010, pp. 33-66.

Cameron, Rondo, Francia y el desarrollo económico de Europa, 1800-1914, Madrid, Tecnós, 1971.

Calvo, Carlos, Colección completa de los tratados, convenciones, capitulaciones, armisticios y otros actos diplomáticos de todos los Estados de la América Latina, comprendidos entre el Golfo de Méjico y el Cabo de Hornos, desde el año de 1493 hasta nuestros días, París, A. Durand, 1862-1869, 11 vols.* [existe un versión completa de esta obra en formato digital que ha realizado la Fundación MAPFRE, en la colección Clásicos Tavera, titulado Textos clásicos y documentación sobre la Independencia de América, J. Alberto Navas Sierra (comp.), Fundación MAPFRE/Tavera, Serie II, vol. 3, Madrid, 2002]. , Anales históricos de la revolución de la América Latina, acompañados de 
los documentos en su apoyo. Desde el año 1808 hasta el reconocimiento de la independencia de ese extenso continente, París, A. Durand, 1864-1867, 5 vols. [existe un versión completa de esta obra en formato digital que ha realizado la Fundación MAPFRE, en la colección Clásicos Tavera, titulado Textos clásicos y documentación sobre la Independencia de América, J. Alberto Navas Sierra (comp.), Fundación Mapfre Tavera, Serie II, vol. 3, Madrid, 2002]. -, Una página de derecho internacional o la América del Sur ante la ciencia del derecho de gentes moderno, París, Librarie A. Durand, 1864.

-, Derecho internacional, teórico y práctico de Europa y América, 2 vols., París, D'Amyot, Durand et Pedone Lauriel, 1868 [se imprimió una edición el mismo año en Buenos Aires. Se publicó una traducción al francés en 1868 y sucesivas ediciones ampliadas en francés en 18701871, 2 vols., 1880-1881, 4 vols. y 1887-1888, 5 vols.].

, Étude sur l'emigration et la colonisation (Réponse à la première du Groupe V, soumise au Congrés International des Sciences Geographiques), París (Orléans), A. Durand et Pedone Lauriel1875.

- L' L'instruction dans la République Argentine. Étude de legislation et de statistiques comparées, Gante (Bélgica), I.S. van Dooslelaer, 1876.

—, Dictionnaire de droit internacional public et privé, Berlín, Piffkamer + Mulhrecht, 1885.

Estrade, Paul, "Del invento de "América Latina” en París por latinoamericanos, 1856-1889", en París y el mundo ibérico e iberoamericano, París, Université de Paris X, Nanterre, 1998, pp. 179-188.

Galeana, Patricia (ed.), Presencia internacional de Juárez, México, Centro de Estudios de México Carso, 2008.

García Mora, Manuel, "The Calvo Clause in Latin American Constitutions and International Law”, Marquette Law Review, vol. 33, núm. 4, 1950, pp. 205-218.

Lajous, Roberta, Historia minima de las relaciones exteriores de México, México, El Colegio de México, 2014.

Limantour, José Yves, "Memoria sobre la vida y obra de D. Carlos Calvo", discurso de incorporación como miembro del Instituto de Francia, París, 1910, 39 pp.

López-Ocón, Leoncio, Biografía de "La América": una crónica hispano-americana del liberalismo democrático español (1857-1886), Madrid, csic, 1987.

Pérez Calvo, Eduardo Ricardo, Vida y trabajos de Carlos Calvo, Buenos Aires, Ediciones Dunken, 1996. 
Pérez Vejo, Tomás, España en el debate público mexicano, 1836-1867: Aportaciones para una historia de la nación, México, El Colegio de México/ ENAH/INAH, 2008.

Phelan, John "Pan-latinismo, French intervention in Mexico (1861-1867) and the genesis of Latin America", en Conciencia y autenticidad históricas (Escritos en homenaje a Edmundo O'Gorman), México, unam, 1968, pp. 279-298, traducido al español por Josefina Vázquez en la revista Latinoamérica (Anuario de Estudios Latinoamericanos), México, UnAm, núm. 2, 1969, pp. 199-141.

Rojas-Mix, Miguel, "Bilbao y el hallazgo de América Latina: unión continental, socialista y libertaria”, Caravelle (Toulouse), núm. 46, 1986.

— Los cien nombres de América, Barcelona, Lumen, 1991.

Sablonierre, Catherine, "El Correo de Ultramar (1842-1886), la ciencia entre labor educativa y la propaganda política”, 2007, 12 pp., en formato digital en http:/ /historiadoresdelaprensa.com.mx/hdp/ files/ 272.pdf

Sepúlveda, César, "La responsabilidad internacional del Estado y la validez de la cláusula Calvo", tesis presentada en la Facultad Nacional de Derecho y Ciencias Sociales, México, 1944.

, Antonio Martínez Báez y Alfonso García Robles, Carlos Calvo: tres ensayos mexicanos, con prólogo de Antonio Gómez Robledo, México, Secretaría de Relaciones Exteriores, Colección del Archivo Histórico Diplomático, 1974, 79 pp.

Shea, Donald, The Calvo Clause: A Problem Of Inter-American and International Law and Diplomacy, Minneapolis, University of Minnesota Press, 1955.

Tamburini, Francesco, "Historia y destino de la Doctrina Calvo: actualidad u obsolenscencia del pensamiento de Carlos Calvo", Revista de Estudios Histórico-Jurídicos, Valparaíso, Chile, Ediciones Universitarios de Valparaíso, vol. 24, núm. 24, 2002, pp. 81-101, http://dx.doi.org/ 10. 4067/S0716-54552002002400005, consultado 13 de abril de 2015.

Torres Caicedo, José María, Unión Latino-Americana, París, Librería Rosa y Bouret, 1865.

——, Ensayos biográficos y de crítica literaria sobre los principales publicistas, historiadores, poetas y literatos de la América latina, 3 vols., París, Baudry, 1865-1868. 